\title{
Private Storage of Common Property ${ }^{1}$
}

\author{
Gérard Gaudet ${ }^{2}$ \\ Département de sciences économiques and Centre de recherche et développement en \\ économique, Université de Montréal, Montréal, Québec, Canada H3C 3J7
}

Michel Moreaux

LEERNA and IDEI, Institut universitaire de France, Université de Toulouse 1, Toulouse, France

and

\author{
Stephen W. Salant
}

Department of Economics, University of Michigan, Ann Arbor, Michigan 48109

Received December 23, 1999; revised June 28, 2000; published online August 21, 2001

\begin{abstract}
Many resources extracted under the rule of capture are not utilized immediately but are stored instead for later use: oil is stockpiled; fish are frozen; groundwater is bottled; rivers are dammed; land, deforested as the way to establish title, remains uncultivated. We examine the positive and normative effects of such storage. Privatization of common property through storage may eliminate inefficiencies altogether but the accelerated extraction it induces may also exacerbate them-even if rapid extraction does not reduce ultimate recovery. Once storage commences, extraction accelerates until the open access reserves are drained. In limiting cases, these speculative acquisitions are instantaneous, the naturally occurring analogue of policy-induced "speculative attacks" studied in the international finance literature. When some reserves are privately owned while others are open access, the order of extraction no longer follows the progression from lowest to highest per-unit cost first noted by O.C. Herfindahl [in "Extractive Resources and Taxation" (M. Gaffney, Ed.), Univ. of Wisconsin Press, Madism (1997)]. Instead, the common property may be extracted in its entirety before any private reserves are extracted even if it has the higher per-unit extraction cost. $\odot 2001$ Elsevier Science (USA)
\end{abstract}

Key Words: rule of capture; free access; tragedy of the commons; speculative attacks; total catch quotas; maximum efficient rate of extraction (MER).

${ }^{1}$ We thank Gary Libecap and Elinor Ostrom for helpful responses to our queries as well as Robert Cairns, Keith Crocker, Robert Deacon, John Hartwick, Murray Kemp, Ngo Van Long, Jean Tirole, David Ulph, and two anonymous referees for comments on a previous draft. Gaudet and Salant were both visiting at INRA-Toulouse when this research was begun. Michel Moreaux acknowledges the financial support of Fondazione ENI Enrico Mattei. Gérard Gaudet also benefited from financial support from the Fonds FCAR du Gouvernement du Québec and the Social Sciences and Humanities Research Council of Canada.

${ }^{2}$ Address correspondence to: Gérard Gaudet, Département de sciences économiques, Université de Montréal, C.P. 6128, Succursale Centre-Ville, Montréal, Québec, Canada H3C 3J7. E-mail: gerard.gaudet@umontreal.ca. 


\section{INTRODUCTION}

In the "Tragedy of the Commons," Hardin [11] describes herdsmen who bring their cows onto a common pasture without regard for the impact their grazing has on other users. The mischief the cows in Hardin's fable can cause, however, is limited. After all, cows have limited capacities. They lack the ability to store massive quantities of grass for their own or others' use in the distant future.

In many real-world situations, however, humans amass huge private caches for future use. Indeed, the ability to store often transforms mere overexploitation into an accelerating and wasteful race to plunder common resources. Waste results not only because acquisitions at such speeds are unnecessarily costly but because they can permanently damage the resource.

Consider some examples. In every state, oil used to be extracted under the "rule of capture." A landowner could claim as his own any oil pumped on his propertyeven if the pool underneath extended far beyond the boundaries of his land. Since oil could be stored privately once pumped, what invariably resulted was a fierce pumping contest-much fiercer than if oil could not be stored.

Oil was stored everywhere-in open tanks, in earthen pits, in steel drums. One company in Smackover, Arkansas, even flooded its fields with oil, creating an oil lake (now an EPA superfund site) 34 acres across and 50 feet deep (Ise [15]). ${ }^{3}$ Production far in excess of the engineers' "maximum efficient rate" (MER) dissipated the gas pressure needed to propel oil to the surface. As a result, most reserves were trapped underground, irrecoverable. ${ }^{4}$

The ability to store creates races in the case of other resources as well. Take the case of fisheries subject to regulations permitting anyone to extract fish until a specified total allowable catch (TAC) is reached, whereupon further fishing is prohibited until the next season. As The Economist [5] observed: “'Open access' can lead to absurd races for fish. In Alaska in the early 1990's anyone could catch sable fish, although the overall total was controlled. As a result, a year's worth of sable fish were usually caught off the coast of Alaska in under a week [our emphasis]. Not only are such scrambles dangerous for fishermen but, since most people will pay less for a frozen fish than a fresh one, they are wasteful too." In the case of the Canadian halibut, under TAC regulation in the 1980s virtually the entire catch was frozen. Such races would have been completely pointless if no one had the ability to freeze and store fish.

The race to capture the remaining quota before some other vessel does results in staggering waste. According to The Economist [5] "Some types of fishing lead to large amounts of 'by-catch,' made up of unwanted species. Nobody knows how much is killed this way, but the best estimate is $22 \mathrm{~m}$ tonnes, roughly a quarter of the total

${ }^{3}$ That storage was a function of the property-rights regime was emphasized by Libecap and Wiggins [22, p. 89]: "Competition for rents necessitated large surface storage. During the first five months of 1928, storage capacity on Hendrick rose from $5,251,000$ barrels to $10,987,000$ barrels at a cost of $\$ 3,842,300$. By contrast, on the neighboring Yates field where private controls limited production, storage was only 783,000 barrels and cost $\$ 274,000$. This was despite a larger potential and greater ultimate oil recovery on Yates."

${ }^{4}$ It is too early to tell if oil in the Caspian Sea will be extracted in an equally chaotic fashion. According to Vinogradov [30, p. 146], to avoid it "Seven international boundaries will have to be delineated. With existing or potential hydrocarbon reservoirs straddling each of these potential boundaries, even agreement on the principles and methods of delimitation might become an insurmountable challenge...." 
wild catch." Much of the targeted species itself is discarded as "too small or otherwise unusable for processing in the automatic processing machines..." (King [17]).

Groundwater usage constitutes another example. ${ }^{5}$ Twenty-nine aquifers underlie $81 \%$ of Texas. Some extend underground as far as South Dakota to the north or Mexico to the south. In 1992, groundwater sources supplied $56 \%$ of all water used in Texas, including $69 \%$ of agricultural needs and $41 \%$ of municipal needs. Yet despite dwindling water supplies, recurrent droughts and the draining of some aquifers, groundwater extracted in this arid state remains subject to the rule of capture. The Supreme Court of Texas recently reaffirmed this rule (Supreme Court of Texas [28]). Groundwater was being extracted not for the current use of some Texas landowner but for the future use of consumers everywhere. The case involved a Perrier subsidiary (Ozarka Natural Spring Water Co.). The Court found that although the company had been "pumping about 90,000 gallons of groundwater per day, seven days a week" from wells near the plaintiff-leaving his own water supply severely depleted-nonetheless the company had an absolute right to pump at whatever rate it wanted. ${ }^{6}$ As the Texas Supreme Court was considering the case, another Perrier subsidiary was seeking permission in Crystal Springs, Florida, to mine groundwater at 30 times the rate in Texas (Karp [16])! If groundwater could not be bottled and sold, mining on this scale would make no sense.

As in the case of other resources, overpumping of groundwater can cause permanent damage both to the targeted resource and to associated resources. If overpumping occurs in coastal areas, it results in saltwater intrusion and a reduction in the overall usable stock. Moreover, overpumping can cause irreversible land subsidence, as it has in Texas (Leake [21]).

In all of these examples, the ability to store privately what can be captured under free access exacerbates the tragedy of the commons. Overexploitation degenerates into an accelerating race, much of what is extracted is wasted, and part of the resource stock may be rendered unusable.

Despite its pivotal role in these cases, storage plays virtually no role in the formal literature on extraction under free access, which has followed the pioneering article by Gordon [10]. The convention is instead to assume that everything extracted under the rule of capture is marketed immediately. ${ }^{7}$

\footnotetext{
${ }^{5}$ Examples abound but space limitations prevent us from considering them in the text. Rivers are stored in reservoirs behind dams. Thus Turkey stores the Euphrates to the detriment of Iraq and Syria while India stores the Ganges to the detriment of Bangladesh. While Bangladesh receives the water which India does not use, the diversion results in high salinity, thereby damaging the resource (Frederick [8] and Asafuddowlah [3]). Koch [18] points out that in South Africa individual farmers use dams to store water captured from rivers which are common property. Elsewhere in the world, land subject to the rule of capture is grabbed but then stored. Land is awarded to homesteaders only if they clear away the forests: "Early clearing is necessary to establish property rights; otherwise the land will be taken by others. This situation has been described as the "race for property rights' " by Angelsen [2, p. 12]. Once acquired, however, it is stored until prices net of transportation costs rise enough to make agricultural production on the land profitable.

${ }^{6}$ For further discussion of this important case, see Eskenazi [6].

${ }^{7}$ Four exceptions should be noted. Sinn [27] presents a noncompetitive model where extractors take as given the time-dated extraction paths of rivals and where aboveground storage is possible. Tornell and Velasco [29] examine a differential game model of common property extraction under restricted access, which they use to explain capital flows from poor countries with high rates of return but weak property rights to rich countries with lower rates of return but secure property rights. Kremer and Morcom [19] consider a renewable stock which can be extracted at a constant marginal cost that strictly increases if
} 
The purpose of our article is to assess both the positive and normative effects of introducing storage into the standard model of extraction under open access. We find that once storage begins, extraction (respectively, fishing) accelerates until the oil pool is drained (respectively, the total allowable catch quota is filled). How long this phase lasts depends on the sensitivity of average costs to increased rates of aggregate extraction. In the limiting case of constant average costs, the extraction contest is so fierce that the common is drained in the instant storage is initiated (a caricature of the 6-day sable fish season). This limiting case is isomorphic to what has become known in the international finance literature as a "speculative attack" in response to attempts to maintain exchange-rate ceilings by selling foreign exchange reserves. ${ }^{8}$

If extraction beyond a MER results in some of the resource being irrecoverable, it may nonetheless be socially optimal to incur this "waste." That is, it may be socially optimal to (1) extract oil at a rate which dissipates pressure and leaves some reserves trapped underground or (2) fish at such a speed that some immature fish are killed in the process. In either case some of the stock of the resource is wasted and rendered unavailable in the future. Even though an engineer would regard any such waste as technically inefficient, there is an optimal amount of waste from an economic point of view. ${ }^{9}$ The rule of capture results in more than this socially optimal amount of waste even in the absence of storage. When storage occurs, however, the fierce extraction race further increases the amount of waste. Hence, although one might have anticipated that access to a new technology (the ability to store) and the assignment of property rights (to stored resources) could only improve social welfare, the resulting equilibrium may be more inefficient. Indeed, even if rapid extraction does not result in waste, the high cost of the accelerating extraction contest may make the equilibrium more inefficient than in the absence of the storage technology.

Much of our analysis concerns the situation where a single oil field is subject to the rule of capture. Equivalently, this base case can be reinterpreted as applying to a single total allowable catch quota governing a fishery. We also consider a hybrid case where one oil pool is extracted under free access and the other oil pools are extracted under private ownership. This hybrid case in turn can be reinterpreted as applying when an unallocated TAC quota regulates a fishery and a set of allocated individual transferable quotas (ITQs) for the same species possibly regulates other fisheries. In this hybrid case, we find that if each pool has the same constant marginal cost of extraction, the common resource must be entirely depleted before the privately owned resources are first utilized; in the reinterpretation, the TAC will

the stock remaining decreases. Finally, Homans and Wilen [13], in a paper just completed as ours is being resubmitted, include storage in their discussion of regulation of the Canadian halibut fishery. Like Kremer and Morcom [19], they assume an extraction technology which is linear in the rate of extraction but subject to depletion effects. This assumption rules out the possibility of speculative attacks; moreover, it creates the possibility that when storage is occurring, extraction can decline even though the price is increasing.

${ }^{8}$ Salant and Henderson [26] discovered the result in their analysis of government attempts to peg the price of gold. Krugman [20] translated Salant and Henderson's result to an international finance context. The international finance literature on speculative attacks has subsequently grown to more than 170 articles. Flood and Marion [7] provide an up-to-date survey.

${ }^{9}$ Note the contrast with standard production theory, where technical efficiency is necessary (but insufficient) for economic efficiency. 
be filled before any of the ITQs are used. Even if the privately owned resources are strictly cheaper to draw down, they may remain untouched until the more costly common reserves are exhausted. This order of extraction contrasts sharply from what Herfindahl [12] found when every pool is privately owned. In that case, a pool with a strictly lower constant marginal cost of extraction must be depleted before a pool with a strictly higher per unit cost is first utilized, and if several pools have the identical per unit cost, there is indifference as to the order in which they are utilized.

For concreteness, we cast our analysis henceforth in terms of oil subject to the rule of capture. However, to remind readers that the principles we develop have wider application, we apply them toward the end of our analysis to total allowable catch quotas regulating fisheries.

The paper proceeds as follows. In Section 2, we examine the positive consequences of introducing storage when oil is extracted subject to the rule of capture. We begin by assuming that all underground reserves are common property but then permit there to be private underground reserves as well. Section 3 concerns social welfare. In that section, we first relax the assumption-maintained throughout Section 2-that the speed of extraction has no effect on ultimate recovery and compare the free-access equilibrium to the social optimum both with and without the opportunity to store. We then ask whether the availability of a storage technology and the extension of property rights to private storage increases welfare. In Section 4 we indicate that our analysis has other applications by showing that it explains the fishing fiascos set in motion by imposing total allowable catch quotas on fisheries. Section 5 concludes the paper.

\section{HOW ACCESS TO ABOVEGROUND STORAGE AFFECTS THE FREE-ACCESS EQUILIBRIUM}

The best place to store oil until you need it is in God's reservoir where He put it and kept it for millions of years until man was given the intelligence to find it. (General Ernest Thompson [Texas Railroad Commissioner from 1932-65] as quoted in O'Connor $[24$, p. 346]).

\subsection{Preliminaries}

Our model has four types of agents: (1) consumers, (2) owners of private underground reserves, (3) stockpilers, and (4) extractors of common property under free access. Throughout, we assume that each of these market participants takes current and future prices as given and acts in his or her self-interest. In a competitive equilibrium, the price path induces suppliers of the resource to satisfy the demands of consumers and stockpilers at every moment. To begin, we briefly review the well-known results of Hotelling [14], Gordon [10], and others concerning optimal behavior of each agent under perfect foresight.

Optimal behavior of "consumers" is summarized by their exogenous demand curve. The demand curve at time $t$ is assumed to be a strictly decreasing, stationary function of the price at time $t$ and to depend on no other prices. For simplicity, we assume that there exists a "choke price," below which demand is positive and above which it is zero. The demand curve can be taken to represent the optimal 
choices, at any given price, of final consumers with quasilinear utility on the one hand or the optimal input choices of firms which purchase the resource and use it to produce output on the other hand.

Optimal extraction by private owners of underground reserves requires that they (1) utilize all of their reserves eventually and (2) extract in such a way that the marginal profit (the price net of the marginal cost) of extracting an additional barrel in present value terms be the same whenever extraction is strictly positive; when extraction is zero, the present value of the marginal profit must be no larger.

If the discounted wealth of stockpilers is maximized, all stockpiles must eventually be liquidated since prices are strictly positive and decumulation of aboveground stocks is assumed to be costless. Given any upward jump in a price path, it is optimal for stockpilers to purchase at an infinite rate for subsequent resale. More generally, purchasing at an infinite rate would be optimal if the percentage rate of increase in the price exceeded the rate of interest. On the other hand, it is optimal for stockpilers to hold zero inventories if price jumps down or, more generally, if the price rises in percentage terms by less than the rate of interest.

Following Gordon [10], we assume that free access to a common property drives the extraction rate up until the average cost of extraction equals the market price $p(t)$ and all rents are dissipated. Under free access, the average cost curve is in effect the "aggregate supply curve" of the extractors until reserves run out, after which their supply at any price is zero. ${ }^{10}$

The requirement that the optimal behavior of these four types of agents be consistent at every moment uniquely determines the equilibrium price path (for prices below the choke price). Our goal will be to predict and then evaluate normatively the equilibrium behaviors of each agent when aboveground storage is feasible and overly rapid extraction may diminish ultimate recovery.

But to illustrate equilibrium analysis in its simplest context, suppose for the moment that aboveground storage is impossible and ultimate recovery is unaffected by the speed of extraction; in addition, assume that all underground reserves are contained in a single pool subject to the rule of capture. In that situation, there will be positive demand at prices below the choke level and this demand can be satisfied only by extraction. Accordingly, the price must remain constant at the point where the demand curve intersects the average cost curve. Once reserves are completely drained, the price must then jump up to choke off demand.

This scenario would constitute a competitive equilibrium in the absence of the ability to store since (1) no agent can do strictly better at the equilibrium prices by alternative behavior and (2) market demand is satisfied at every instant. But if agents could store as private property aboveground stocks extracted under the rule of capture, it would not be an equilibrium. For, in that situation, foresighted agents would attempt to make infinite purchases immediately before the upward price jump for resale after the jump. Since the supplies would not exist to satisfy this infinite demand, the scenario we are describing could not remain an equilibrium once aboveground storage became feasible. The equilibrium in that case will involve storage of extracted reserves.

\footnotetext{
${ }^{10}$ Alternatively, one can regard the average cost of extraction from the oil field as a function not merely of aggregate extraction but also of the remaining reserves; under this interpretation, the average cost curve jumps up when the reserves are depleted and coincides with the vertical axis.
} 


\subsection{One Common Pool}

When storage is possible, the equilibrium price path must have no upward jumps. Moreover, when inventories are held above ground the price must rise by the rate of interest. ${ }^{11}$ Given these considerations, the equilibrium price path once storage is introduced must be composed of two phases. During the first, the real price is constant at a level which causes extraction at each instant to match consumer demand so that no stocks accumulate. Denote this level as $p^{*}$, the vertical component of the point where the demand curve $(D(p))$ cuts the aggregate extraction schedule $\left(A C^{-1}(p)\right)$. During the second phase, the price rises from $p^{*}$ at the rate of interest until consumer demand is choked off. Given this rate of price increase, people would just be compensated, in the absence of storage costs, for the interest they forego in holding aboveground inventories. If the reserves subject to the rule of capture are sufficiently small initially, the first phase disappears entirely.

The second phase itself must be composed of two intervals. During the first, extraction exceeds demand (since $p>p^{*}, A C^{-1}(p)>D(p)$ ) and the excess is added to private stockpiles. Indeed extraction must continually accelerate over time since the price is rising and the extraction schedule $\left(A C^{-1}(p)\right)$ is upward-sloping; moreover, since the demand curve $(D(p))$ is downward-sloping, less is consumed as time passes; for both reasons, additions to storage increase over time.

If this situation persisted until the choke price was reached, it would clearly be a disequilibrium since the accumulated stocks would never be resold and it would have been more profitable not to buy them. What prevents the continual accumulation of stocks is the exhaustion of underground reserves. At precisely the moment when reserves disappear and extraction jumps down to zero, decumulation of aboveground stocks jumps up by an offsetting amount. Consequently, no discontinuity in the price path results. In the second interval, private inventories are decumulated to satisfy market demand until the choke price is reached.

This constitutes an equilibrium because market demand is satisfied at every instant and each agent's behavior is optimal: the consumers are on their demand curve at all times, the extractors are on their aggregate "supply curve," and the stockpilers are behaving optimally by (1) postponing their activities until the phase when the price rises at the rate of interest and (2) liquidating their stocks eventually.

We now describe this equilibrium more formally. Denote the length of the first phase as $\theta$. Let $H(p, \theta)$ denote the cumulative demand when the price remains at $p^{*}$ for $\theta$ weeks and then grows from $p$ at the rate of interest until demand is choked off:

$$
H(p, \theta)=\theta D\left(p^{*}\right)+\int_{u=0}^{\infty} D\left(p e^{r u}\right) d u
$$

\footnotetext{
${ }^{11}$ For simplicity, we assume that storage is costless and that $100 \%$ of each stored barrel can be retrieved. In reality, part of the stockpiled oil was often lost through leakage, seepage, fire, or evaporation. Suppose a fraction $\delta$ of what remains in storage is lost at each instant $t$. Then the price which would make someone indifferent between selling initially and storing until $t$ would have to be increased to $P(t)=P(0) e^{(r+\delta) t}$. Hence, to take account of such losses, simply replace the exogenous real interest rate in our analysis by $r+\delta$.
} 
Let $S_{0}^{c *}$ be the initial reserves which would just satisfy cumulative demand at a price path starting at $p^{*}$ and rising at the rate of interest. That is,

$$
S_{0}^{c *}=H\left(p^{*}, 0\right) .
$$

Recall that the initial size of the reserves subject to the rule of capture is denoted $S_{0}^{c}$. We distinguish two cases: $S_{0}^{c} \geq S_{0}^{c *}$ and $S_{0}^{c}<S_{0}^{c *}$.

Case 1. Suppose that $S_{0}^{c} \geq S_{0}^{c *}$, and let $\theta^{*}$ denote the equilibrium value of $\theta$. Then

$$
\theta^{*}=\frac{S_{0}^{c}-S_{0}^{c *}}{D\left(p^{*}\right)},
$$

and the equilibrium price path is

$$
p(t)= \begin{cases}p^{*} & \text { if } 0 \leq t<\theta^{*} \\ p^{*} e^{r\left(t-\theta^{*}\right)} & \text { otherwise. }\end{cases}
$$

Since, as noted above, extraction exceeds demand as long as reserves remain and $p>p^{*}$, there exists some $\nu^{*}>0$ such that

$$
\int_{u=0}^{\nu^{*}} A C^{-1}\left(p^{*} e^{r u}\right) d u=S_{0}^{c}-\theta^{*} D\left(p^{*}\right)=S_{0}^{c *} .
$$

Extraction from the common (denoted $x^{c}(t)$ ) is constant until $t=\theta^{*}$ and then strictly increases until reserves are exhausted $\nu^{*}$ weeks later; at that point, extraction jumps discontinuously to zero. That is,

$$
x^{c}(t)= \begin{cases}A C^{-1}\left(p^{*}\right)=D\left(p^{*}\right) & \text { if } 0 \leq t \leq \theta^{*} \\ A C^{-1}(p(t))>D(p(t)) & \text { if } \theta^{*}<t \leq \theta^{*}+\nu^{*} \\ 0 & \text { otherwise. }\end{cases}
$$

The equilibrium is depicted in the three panels of Fig. 1. Fig. 1a depicts the upwardsloping average cost function, the downward-sloping demand function, and the vertical component of their point of intersection, $p^{*}$. Fig. $1 \mathrm{~b}$ depicts the equilibrium price path as a continuous function of time. Fig. 1c depicts the paths of extraction and demand. When the former exceeds (respectively, falls short of) the latter, the difference goes into (respectively, comes out of) private stockpiles.

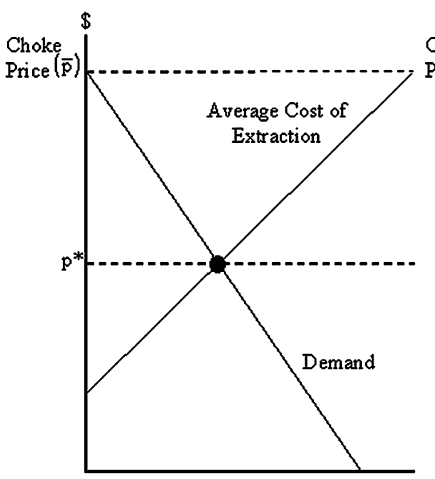

Quantity

(a)

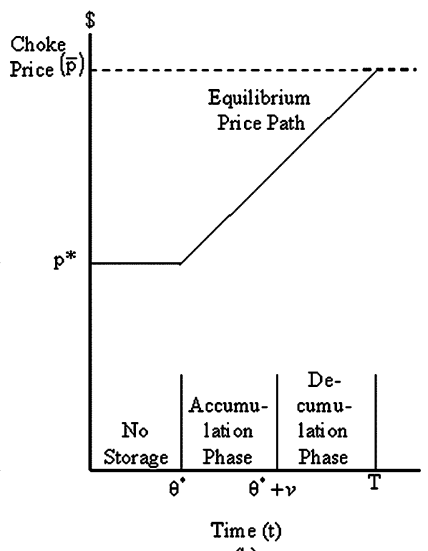

(b)

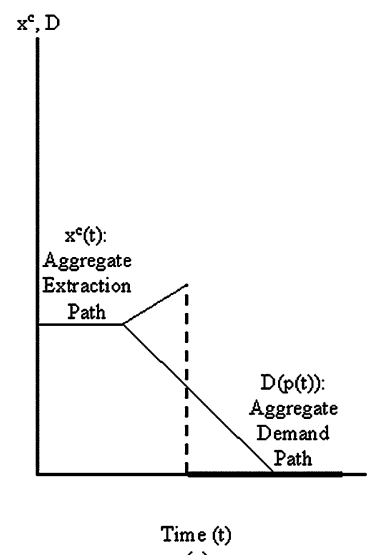

(c)

FIGURE 1 
Case 2. If the initial reserves subject to the rule of capture are sufficiently small $\left(S_{0}^{c}<S_{0}^{c *}\right)$, then the second phase commences immediately. Let $\alpha^{*}>p^{*}$ be the initial price on a path rising at the rate of interest and inducing a cumulative demand of $S_{0}^{c}$. That is, $\alpha^{*}$ is implicitly defined by the equation

$$
S_{0}^{c}=H\left(\alpha^{*}, 0\right) \text {. }
$$

The price at any time $t \geq 0$ is simply $p(t)=\alpha^{*} e^{r t}$. Since extraction strictly exceeds demand as long as the common contains unexploited reserves, the length of time during which extraction occurs and private stocks accumulate $\left(\nu^{*}\right)$ is defined by

$$
\int_{u=0}^{\nu^{*}} A C^{-1}\left(\alpha^{*} e^{r u}\right) d u=S_{0}^{c}<S_{0}^{c *},
$$

an obvious specialization of (5).

\subsection{Many Common Pools}

The price path which results when there are multiple oil fields subject to the rule of capture, each with a different cost of extraction, is qualitatively similar. It is continuous and consists of horizontal segments at different heights, each linked by phases where the price rises at the rate of interest. The price must be constant when no storage occurs since neither the demand curve nor the average cost curve of any pool with strictly positive reserves changes over time. The level of this constant price depends on the horizontal sum of the average cost curves of those pools with positive reserves. When storage does occur, the price must rise by the rate of interest from one plateau to the next to induce the holding of inventories. ${ }^{12}$

\subsection{The Hybrid Case: Private Pools as Well as a Common Pool}

When, in addition to property subject to the rule of capture, there exist private underground reserves, the equilibrium is more complicated. Unlike the agent extracting from reserves subject to the rule of capture, it is in the interest of owners of private reserves to take account of the fact that when they extract a unit of the resource today they forego the opportunity of extracting it tomorrow. Hence their full marginal cost at time $t$ is composed of the marginal cost of extraction as such, which we will assume constant and denote $k$, plus the shadow value of leaving the resource in the ground for future extraction, which we denote $e^{r t} \mu$. For any given level of reserves subject to the rule of capture, $\mu$ is a monotone decreasing function of the initial level of the private reserves, tending to zero as they tend to infinity.

It is useful to distinguish two regimes: $p^{*} \leq k+\mu$ and $p^{*}>k+\mu$. In the former regime $\left(p^{*} \leq k+\mu\right)$, we will see that the extraction of private underground reserves does not commence until those subject to the rule of capture are entirely drained and all aboveground storage ceases as well. This must occur if $p^{*} \leq k$ and may

\footnotetext{
${ }^{12}$ In cases where the order of exhaustion of the pools is obvious, the price path is easily constructed. One example where the order of exhaustion is clear is when each pool has a different but constant average cost. In that case the pools would be exhausted in order of their costs with the lowest cost pool exhausted first. Another example would be when the average cost curves are upward-sloping but do not intersect and the pool with the larger supply at any price has the smaller reserves. In that case, the pools would be depleted in order of their size with the smallest pool depleted first.
} 
occur even if $p^{*}>k$. The equilibrium price path resembles the paths discussed in the previous section but with a final phase tacked on at the end during which all of the extraction of private underground reserves occurs. We use the same symbol to denote a variable corresponding to the previous situation without private reserves but add a circumflex to distinguish the situation with private as well as common reserves. Whether the price path has a horizontal segment lasting $\hat{\theta}^{*}$ weeks at $p^{*}$ or instead begins at $\hat{\alpha}^{*}>p^{*}$ and rises at the rate of interest depends as before on the sizes of the initial reserves. But in either case, aboveground storage ceases before the choke price is reached and a final phase then commences during which all the extraction of private underground reserves occurs.

In the latter regime $\left(p^{*}>k+\mu\right)$, some private extraction of underground reserves must occur in a preliminary phase before the price rises to $p^{*}$. Either all the private extraction can occur during this preliminary phase or, alternatively, some can occur then and the rest only after stored inventories are sold off. If private extraction occurs at prices below $p^{*}$, the price must rise at a rate sufficient to make the private extractors indifferent when they sell. As the price increases, the excess of demand over extraction from the common declines to zero. Private extraction, which covers the deficit, must decline to zero as $p^{*}$ is reached.

Note that in either case, it can never be optimal for the owner of a private underground stock to be extracting while private storage occurs. For if price is growing at a rate which makes profitable the storage of inventories above ground, it also makes profitable the withholding of extraction of underground reserves.

We now describe this equilibrium more formally. The determination of the lengths of each phase depends on the two initial reserves. Let $S(t)$ denote the remaining private reserves at date $t$ and let $S_{0}$ denote the initial private reserves. Let $\tau$ denote the date at which private storage of the common resource begins. Define $l(p, S(\tau))$ as the solution to

$$
\int_{u=0}^{\infty} D\left(\left(p e^{r l}-k\right) e^{r u}+k\right) d u=S(\tau)
$$

That is, $l$ is the length of time a price would have to rise in the storage phase at the rate of interest, from initial level $p$, so that if the price subsequently rose at the slower rate required to make the private extractors indifferent, this final phase of the price path would induce a cumulative demand equal to the private reserves left under ground at the date storage begins. Note that $l(p, S(\tau))$ is well defined only for $S(\tau)>0$.

Let $\widehat{H}(p, \hat{\theta}, l(p, S(\tau)))$ denote that portion of cumulative demand induced when the price remains at $p^{*}$ for $\hat{\theta}$ weeks and then grows from $p$ at the rate of interest for $l(p, S(\tau))$ weeks:

$$
\widehat{H}(p, \hat{\theta}, l(p, S(\tau)))=\hat{\theta} D\left(p^{*}\right)+\int_{u=0}^{l(p, S(\tau))} D\left(p e^{r u}\right) d u .
$$

Clearly, when $p^{*} \leq k+\mu$, no extraction from the private reserves will have occurred when private storage from the common resource begins and so $\tau=\hat{\theta}$ and $S(\tau)=S_{0}$.

Finally, let $\widehat{S}_{0}^{c *}$ be the common reserves demanded cumulatively along a price path starting at $p^{*}$ and rising immediately from $p^{*}$ at the rate of interest for $l\left(p^{*}, S(\tau)\right)$ weeks. That is,

$$
\widehat{S}_{0}^{c *}=\widehat{H}\left(p^{*}, 0, l\left(p^{*}, S(\tau)\right)\right) .
$$

We now consider successively the two regimes described above. 
Regime 1. If $p^{*} \leq k+\mu$, we may, as in the situation with no private underground reserves, distinguish two cases, depending on whether $S_{0}^{c} \geq \widehat{S}_{0}^{c *}$ or $S_{0}^{c}<\widehat{S}_{0}^{c *}$.

Whenever $S_{0}^{c} \geq \widehat{S}_{0}^{c *}$, then

$$
\hat{\theta}^{*}=\frac{S_{0}^{c}-\hat{S}_{0}^{c *}}{D\left(p^{*}\right)}
$$

and the equilibrium price path is

$$
p(t)= \begin{cases}p^{*} & \text { if } 0 \leq t<\hat{\theta}^{*} \\ p^{*} e^{r\left(t-\hat{\theta}^{*}\right)} & \text { if } \hat{\theta}^{*} \leq t<\hat{\theta}^{*}+l\left(p^{*}, S_{0}\right) \\ \left(p^{*} e^{r l\left(p^{*}, S_{0}\right)}-k\right) e^{r\left(t-\hat{\theta}^{*}-l\left(p^{*}, S_{0}\right)\right)}+k & \text { otherwise. }\end{cases}
$$

If, on the other hand, the initial reserves in the common are sufficiently small $\left(S_{0}^{c}<\widehat{S}_{0}^{c *}\right)$, the storage phase commences immediately. Define the initial price $\left(\hat{\alpha}^{*}\right)$ as

$$
S_{0}^{c}=\widehat{H}\left(\hat{\alpha}^{*}, 0, l\left(\hat{\alpha}^{*}, S_{0}\right)\right)
$$

Then the equilibrium price path is

$$
p(t)= \begin{cases}\hat{\alpha}^{*} e^{r t} & \text { if } 0 \leq t<l\left(\hat{\alpha}^{*}, S_{0}\right) \\ \left(\hat{\alpha}^{*} e^{r l\left(\hat{\alpha}^{*}, S_{0}\right)}-k\right) e^{r\left(t-l\left(\hat{\alpha}^{*}, S_{0}\right)\right)}+k & \text { otherwise. }\end{cases}
$$

Regime 2. If $p^{*}>k+\mu$, then the price path is more complex than that in regime 1 . We will now have

$$
\hat{\theta}^{*}<\frac{S_{0}^{c}-\widehat{S}_{0}^{c *}}{D\left(p^{*}\right)} \text { and } \tau^{*}>\hat{\theta}^{*}
$$

and the equilibrium price path will be

$$
p(t)= \begin{cases}\left(p^{*}-k\right) e^{r\left(t-\left(\tau^{*}-\hat{\theta}^{*}\right)\right)}+k & \text { if } 0 \leq t<\tau^{*}-\hat{\theta}^{*} \\ p^{*} & \text { if } \tau^{*}-\hat{\theta}^{*} \leq t<\tau^{*} \\ p^{*} e^{r\left(t-\tau^{*}\right)} & \text { if } \tau^{*} \leq t<\tau^{*}+l\left(p^{*}, S\left(\tau^{*}\right)\right) \\ \left(p^{*} e^{r l\left(p^{*}, S\left(\tau^{*}\right)\right)}-k\right) e^{r\left(t-\tau^{*}-l\left(p^{*}, S\left(\tau^{*}\right)\right)\right)}+k & \text { otherwise. }\end{cases}
$$

Some exceptional price path configurations may arise in this regime. For instance, it is conceivable that the private reserves are completely drawn down $(S(\tau)=0)$ as the price path reaches $p^{*}$. The rest of the path is then exactly what we described in the absence of private underground reserves, for the case of sufficiently large initial common reserves. Formally, the interval $l\left(p^{*}, 0\right)$ is not defined nor is the last phase. From $\tau^{*}$ on, the price path therefore follows $p(t)=p^{*} e^{r\left(t-\tau^{*}\right)}$. Alternatively, the initial private reserves may be so large as to completely dominate the determination of the price path, resulting in the disappearance of the two middle stages and an equilibrium price path given by $p(t)=\left(p^{*}-k\right) e^{r t}+k$. Such a path induces private extraction throughout and common property extraction only if the price is below $p^{*}$. Hence, the second phase of private extraction follows the first with no intermediate phase of storage. As price rises to some $\tilde{p} \leq p^{*}$, the commons is exhausted and 
private extraction jumps up by $A C^{-1}(\tilde{p})$ to replace it. ${ }^{13}$ Formally, $\theta^{*}=0$, from which it follows that necessarily $l\left(\tilde{p}, S\left(\tau^{*}\right)\right)=0$. Notice that whereas in Regime 1 above, $\theta^{*}=0$ could only occur for $S_{0}^{c}=\widehat{S}_{0}^{c *}$, it now occurs only when common reserves are completely drawn down as $\tilde{p}$ is reached. This explains why $l\left(\tilde{p}, S\left(\tau^{*}\right)\right)$ must vanish, since there can be no storage phase if there are no reserves left in the common pool. ${ }^{14}$

It is interesting to consider the situation in which the common pool is also extracted at constant marginal cost. We continue to denote the constant marginal cost of extracting from the private property as $k$; the constant marginal cost of extracting from the common property is simply $p^{*}$ since the horizontal average cost curve will intersect the demand curve at that point. Two possibilities are of interest: $p^{*}=k$ and $p^{*}>k$.

If $p^{*}=k$, the analysis of Regime 1 applies: the common reservoir must be exhausted and the aboveground stocks from it depleted before extraction of the private pool commences. This contrasts with the standard situation of two privately owned pools which can be extracted at identical marginal costs: there would then be an indeterminacy in the competitive equilibrium as to the source of the aggregate output in a given period. If $p^{*}>k$ then, as we have seen, it is possible in a competitive equilibrium for the common property to be entirely drained before extraction from the private property commences. This occurs whenever $p^{*}<k+\mu$. This order of extraction contrasts with the standard result of Herfindahl [12] that, when both pools are privately owned, the pool which is cheaper to extract must be exhausted before the extraction begins on the higher-cost pool.

\subsection{The Speed of Privatization: Naturally Occurring Speculative Attacks}

Whether or not there are private reserves, if the initial reserves of common property are sufficiently large, extraction from them will occur at a uniform rate for an interval of time. But the initiation of storage signals the beginning of the pumping race. Extraction increases for $\nu^{*}$ more weeks as the price rises from $p^{*}$ at the rate of interest and stocks accumulate at an increasing rate above ground. Accumulation stops only when the common is completely drained of reserves, at which point decumulation of the private stockpiles begins. When these are completely drawn down,

\footnotetext{
${ }^{13}$ The scenario described in the text relies heavily on the assumption that the marginal cost of extraction is constant. Denote the total cost of private extraction by $k(\cdot)$. As long as the marginal cost of satisfying the full demand from private reserves is any larger than the marginal cost of extracting zero $\left(k^{\prime}\left(D\left(p^{*}\right)\right)>k^{\prime}(0)\right)$, some reserves extracted from the commons must be stored. Suppose this is not the case. Then at the moment when the common property is drained and its rate of exploitation jumps from $A C^{-1}(\tilde{p})>0$ to zero, the rate of private extraction must-in the absence of any storage-jump in the opposite direction by the same amount. But given our assumption about the marginal cost curve of private extractors, their marginal profit in the instant before these offsetting jumps would be strictly larger than marginal profit in the instant after them: the price would be $\tilde{p}$ in either case but the upward jump in extraction would, by hypothesis, induce some increase in the marginal cost. But since the marginal profit after the jumps is smaller, private extractors would alter their behavior-extracting less after the jump and more before it than we hypothesized. But what we hypothesized was necessary if supply is to equal demand in the absence of storage. The conclusion is inescapable: storage of reserves extracted from the commons must occur in the equilibrium as long as $k^{\prime}(D(\tilde{p}))>k^{\prime}(0)$.

${ }^{14}$ The demonstration is straightforward that, for any pair of initial reserves (one private and the other common), a unique competitive equilibrium price path exists. We omit this proof to conserve journal space but will make it available upon request.
} 
consumption either ceases altogether or is satisfied entirely by private extraction depending on the situation under consideration.

Notice a striking characteristic of these equilibria. The length of the interval during which private inventories are accumulated in either situation $\left(\nu^{*}\right)$ depends on the slope of the average cost curve. If the average cost curve has a small positive slope, the frenzied race to drain the common and accumulate its contents as private stocks requires a short time interval. If instead the average cost curve is horizontal, the accumulation is instantaneous $\left(\nu^{*}=0\right.$.). This means that after declining at the finite rate $D\left(p^{*}\right)$, the remaining reserves subject to the rule of capture are suddenly depleted at an infinite rate in one frenzied instant and then stored privately. In cases where the initial price exceeds $p^{*}$ because initial reserves are sufficiently small, the frenzied accumulation begins immediately.

This precipitous behavior is a manifestation of what Salant and Henderson [26] first identified as a "speculative attack" in connection with their analysis of the run on the government stockpiles of gold used to defend the official price ceiling of $\$ 35$ per ounce. A striking difference, however, is that here the speculative attack occurs in the absence of any government policy: it is naturally occurring. ${ }^{15}$

\subsection{Reserve Uncertainty: Multiple Attacks}

In the more realistic situation where there is uncertainty about the size of the reserves subject to the rule of capture, multiple speculative attacks should occur in the absence of any government intervention. ${ }^{16}$ Consider the case of a common property which can be extracted at constant average (equals marginal) cost $p^{*}$. Suppose each potential stockpiler believes that the reserve level is $R_{i}$ with probability $\pi_{i}$ for $i=1, \ldots, n .^{17}$ As a convenience, let $R_{0}=0$. Define the increment between reserve levels as $\Delta_{i}=R_{i}-R_{i-1}$ for $i=1, \ldots, n$. Denote the probability that initial reserves are exactly $R_{i}$, conditional on there being at least $R_{i}$, as

$$
\hat{\pi}_{i}=\frac{\pi_{i}}{\sum_{j=i}^{n} \pi_{j}} \quad \text { for } i=1, \ldots, n .
$$

Note that $\hat{\pi}_{n}=1$.

Let $P(S, \tilde{p})$ be the initial price on a path which rises at the rate of interest until it reaches $\tilde{p}$ and induces cumulative demand of $S$. Let $T(S, \tilde{p})$ denote the length of time required for the depletion of the $S$ units of reserves to occur. $P(S, \tilde{p})$ has the following properties: (1) it is continuous in $S$, (2) it is strictly decreasing in $S$, (3) $P\left(S_{0}^{c *}, \bar{p}\right)=p^{*}$, and (4) $P(S, \tilde{p}) \leq \tilde{p}$ with equality if and only if $S=0$.

Define $S_{i}^{*}$ as the solution to the equation

$$
p^{*}=\hat{\pi}_{i} P\left(S_{i}^{*}, \bar{p}\right)+\left(1-\hat{\pi}_{i}\right) P\left(S_{i}^{*}, p^{*}\right) \quad \text { for } i=1, \ldots, n .
$$

Given the four properties of the $P(\cdot)$ function, this equation uniquely defines $S_{i}^{*} \in$ $\left(0, S_{0}^{c *}\right)$ for $i=1, \ldots, n$. It follows that the price will jump above $p^{*}$ if it turns out

\footnotetext{
${ }^{15}$ In the case of multiple pools of reserves subject to the rule of capture discussed in Section 2.3, if the average cost of extraction at each pool is constant, then each storage phase commences with an attack: there are multiple speculative attacks, but never on the same pool.

${ }^{16}$ The case analyzed below can easily be translated into the context of international finance. There the common is replaced by a government committed to selling whatever reserves are necessary to place a ceiling on its exchange rate and speculators are uncertain about the size of the government's reserves.

${ }^{17}$ For the corresponding analysis of socially optimal extraction with unknown reserves, see Gilbert [9].
} 
that reserves are exhausted but will collapse below $p^{*}$ if there turn out to be more reserves underground. Assume that $\Delta_{i}-S_{i}^{*}>0$ for $i=1, \ldots, n$.

Let $i=1$. In the competitive equilibrium, extraction continues for $\Theta_{i}^{*}=\left(\Delta_{i}-S_{i}^{*}\right) /$ $D\left(p^{*}\right)$ weeks with the price equal to $p^{*}$. At that point, speculators suddenly purchase $S_{i}^{*}$. If reserves are exhausted, the price jumps up to $P\left(S_{i}^{*}, \bar{p}\right)>p^{*}$ and the inventories acquired are sold off gradually until, $T\left(S_{i}^{*}, \bar{p}\right)$ weeks later, the choke price is reached. The other possibility is that speculators infer that more reserves remain underground. The price then collapses to $P\left(S_{i}^{*}, p^{*}\right)<p^{*}$ and extraction ceases for $T\left(S_{i}^{*}, p^{*}\right)$ weeks until the inventories acquired in the attack are worked off and the price of $p^{*}$ is regained. At that point, extraction resumes and the entire process evolves in the same way with $i=2 \ldots$ This behavior is optimal for the speculators given the sequence of state-contingent prices since they acquire stocks at a price equal to the discounted mean of the prices they expect to obtain when they sell and then liquidate those stocks before the price stops rising, a phase they can perfectly foresee given what they learn immediately after the most recent attack.

Suppose the true state is $R_{n}$. Then, immediately after the $n-1$ st attack, reserves remain and everyone infers that there were initially $R_{n}$ reserves of which $\Delta_{n}$ remain. There is, therefore, no longer any uncertainty about the size of the reserves subject to the rule of capture. This returns us precisely to the certainty case described above. In this event, the previous two equations imply that $\hat{\pi}_{n}=1$ and $S_{n}^{*}=S_{0}^{c *}$. The price immediately after the final attack is therefore $P\left(S_{n}^{*}, \bar{p}\right)=p^{*}$, as we concluded earlier. In terms of the generalization to uncertainty just summarized, since there is no downside risk when the $n$th attack occurs, there is no upward price jump necessary immediately following the attack to compensate the speculators for a potential capital loss.

\section{WELFARE COMPARISONS}

When many different landholdings lay over an oil pool, unregulated production soon turned into a pumping contest, with each individual drilling as many wells as possible and running them wide open. This was the practice in Texas for a generation after Spindletop. In every reservoir, it resulted in a huge waste because it guaranteed dissipation of reservoir energy. Once 5 or $10 \%$ of the original oil had been produced, the water or gas drive was expended and the wells stopped flowing. Texas is dotted with small towns like Borger that went from boomtown to ghost town in a few years, because the frantic pace of development in their fields used up the pressure in their reservoirs. (Prindle [25, p. 24])

Until now, we have abstracted from the fact that rapid extraction can damage the resource, reducing what is available in the future. In the case of oil, extraction beyond a threshold rate often weakens the gas or water drive propelling oil to the surface, thus reducing ultimate recovery. This threshold rate is referred to in the engineering literature as the MER. ${ }^{18}$ We have not mentioned it before because its existence alters neither the extraction response under free access to any given price nor the qualitative characteristics of the intertemporal equilibrium. ${ }^{19}$ The existence of an MER threshold, however, does affect the qualitative features of the socially

${ }^{18} \mathrm{McFarland}[23]$ provides a valuable survey of the MER concept in the engineering literature.

${ }^{19}$ It would alter the magnitudes of $\theta^{*}$ and $\nu^{*}$ of Section 2.1 since initial reserves must now equal the sum of cumulative demand and the reserves that are wasted along the proposed equilibrium extraction path. 
optimal extraction plan. We discuss this plan in the first section below and then compare it to equilibrium under free access.

Hotelling [14] and others derived the socially optimal extraction plan under the assumption that there is no MER threshold. Suppose, however, that such a threshold in fact exists and refer to reserves rendered irrecoverable as "leakage." If the extraction program Hotelling derived never exceeds the MER threshold, it would still be optimal. If it does sometimes exceed the MER threshold, Hotelling's proposed extraction program is infeasible and the socially optimal plan will involve some leakage. As we show, however, when the pool is extracted under free access (with or without storage), leakage necessarily exceeds the optimal level. Private storage results in even smaller ultimate recovery.

This raises the question of whether the opportunity to store as private property oil extracted under the rule of capture improves welfare or whether, as General Thompson suggested, it is always better to leave the oil in "God's reservoir" until it is needed. We resolve this issue in the final section.

\subsection{First Best: The Social Optimum When Speed of Extraction Reduces Ultimate Recovery}

Let $x$ denote the rate at which a resource is extracted from a reservoir for consumption, storage, or other uses. Assume that, if this rate of extraction exceeds a critical threshold (denoted $E$ ), some underground reserves are permanently lostwith the rate of loss proportional to the gap between the extraction rate and the threshold. When extraction is sufficiently hasty, underground reserves decline more rapidly than usable resources reach the surface: $\frac{d S}{d t}=-x-\gamma \max \{0, x-E\}$. Denote by $U(\cdot)$ the instantaneous gross benefit function and assume that the social and market rates of interest $(r)$ coincide. Then, in the absence of a storage technology, socially optimal extraction solves the dynamic optimization problem

$$
\max _{x(t)} \int_{0}^{\infty}[U(x(t))-C(x(t))] e^{-r t} d t
$$

subject to

$$
\begin{aligned}
& \frac{d S}{d t}=-x(t)-\gamma \max \{0, x(t)-E\} \\
& x(t) \geq 0, S(t) \geq 0 \quad \text { and } \quad S(0)=S_{0},
\end{aligned}
$$

where $C(x)=x A C(x)$

Let $\lambda$ be the discounted shadow value of leaving the resource in the ground for future extraction. ${ }^{20}$ According to the maximum principle, the optimal extraction rate $(x \geq 0)$ maximizes $U(x)-C(x)-\lambda e^{r t}(x+\gamma \max \{0, x-E\})$ at each instant. Denote the extraction rate maximizing this function as $x(t, \lambda)$. When the reserve constraint is binding, the multiplier associated with the optimal program (denoted $\left.\lambda^{*}\right)$ solves the endpoint condition

$$
\int_{0}^{\infty}\left[x\left(t, \lambda^{*}\right)+\gamma \max \left\{0, x\left(t, \lambda^{*}\right)-E\right\}\right] d t=S_{0} .
$$

\footnotetext{
${ }^{20}$ Since $S(t)$ does not appear in the functional to be maximized, $\lambda$ is a constant.
} 
The function maximized at each instant (the Hamiltonian) is continuous, strictly concave, but kinked at $x=E$. One of the following conditions will hold at each $t$ if the program is socially optimal,

$$
\begin{array}{rll}
x>E>0 & \text { and } & U^{\prime}(x)-C^{\prime}(x)-\lambda e^{r t}(1+\gamma)=0, \text { or } \\
x=E & \text { and } & \gamma \lambda e^{r t} \geq U^{\prime}(x)-C^{\prime}(x)-\lambda e^{r t} \geq 0, \text { or } \\
E>x>0 & \text { and } & U^{\prime}(x)-C^{\prime}(x)-\lambda e^{r t}=0, \text { or } \\
x=0 & \text { and } & U^{\prime}(0)-C^{\prime}(0)-\lambda e^{r t} \leq 0 .
\end{array}
$$

This solution may be visualized with the aid of Fig. 2. In the diagram, we plot the downward-sloping schedule of marginal benefits $\left(U^{\prime}(x)\right)$ and the upward-sloping schedule of full marginal costs. The latter is discontinuous. For $x<E$, the full marginal cost is $C^{\prime}(x)+\lambda e^{r t}$. For $x>E$, however, it is $C^{\prime}(x)+\lambda e^{r t}(1+\gamma)$. The full marginal cost is undefined at $x=E$ since the full total cost function is kinked at that point. Optimal extraction may be read from Fig. 2 as the horizontal component of the intersection point of the two curves. There are three cases of interest.

If the initial stock is sufficiently small, then at $t=0$ the two curves intersect to the left of $E$. The smallest multiplier inducing initial extraction of $E$ is $\tilde{\lambda}=$ $U^{\prime}(E)-C^{\prime}(E)$. Hence, the largest initial stock inducing this outcome is $\widetilde{S}_{0}$, the implicit solution to the following equation: $\int_{0}^{\infty} x(t, \tilde{\lambda}) d t=\widetilde{S}_{0}$. For any initial stock $S_{0} \in\left[0, \widetilde{S}_{0}\right)$, extraction commences with $x(0) \in[0, E)$. Over time, the upwardsloping full marginal-cost curve shifts up and the intersection point of the two curves moves leftward-implying that optimal extraction declines monotonically to zero.

At the other extreme, if the initial stock is sufficiently large, then extraction commences with $x(0)>E$. In that case, extraction declines monotonically to $E$, lingers there for an interval of $d$ years, and then declines to zero. The largest multiplier inducing initial extraction of $E$ is $\bar{\lambda}=\left(U^{\prime}(E)-C^{\prime}(E)\right) /(1+\gamma)$. Hence, the smallest initial stock inducing this outcome is $\bar{S}_{0}$, the implicit solution to the following equation: $\int_{0}^{\infty}[x(t, \bar{\lambda})+\gamma \max \{0, x(t, \bar{\lambda})-E\}] d t=\bar{S}_{0}$. For any initial stock $S_{0} \in\left(\bar{S}_{0}, \infty\right)$ extraction commences with $x(0) \in(E, \infty)$.

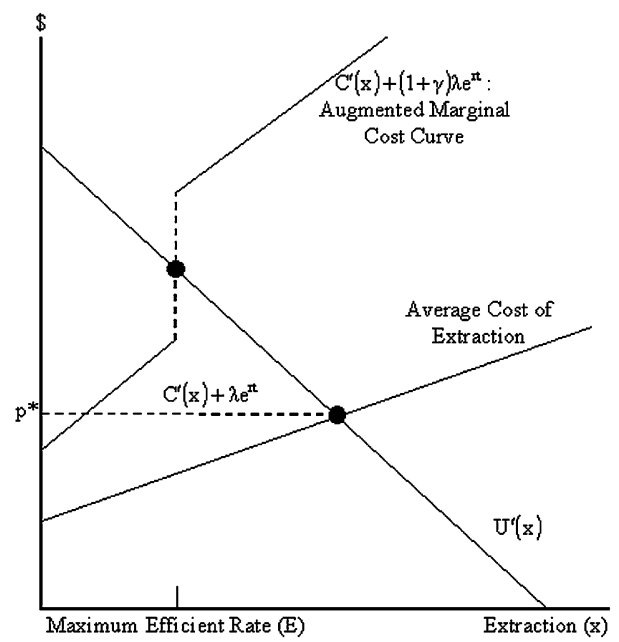

FIGURE 2 
For initial stocks of intermediate size $\left(S_{0} \in\left[\widetilde{S}_{0}, \bar{S}_{0}\right]\right)$, extraction commences with $x(0)=E$. The full marginal cost associated with larger extraction would strictly exceed the resulting marginal benefit while the full marginal cost of smaller extraction falls short of the marginal benefit. In this situation, extraction remains at $E$ for that interval of time during which the point of intersection of the curves in Fig. 2 occurs on the vertical segment of the full marginal-cost curve; thereafter, extraction declines monotonically to zero.

Suppose that the initial stock is sufficiently large so that extracting faster than the MER at the outset is socially optimal. Then, the marginal benefit of the resource net of the cost of extraction grows at the rate of interest during the initial phase, remains constant for $d$ years, ${ }^{21}$ and resumes its growth at the rate of interest during the final phase. The optimality of this path merits some discussion. Since the net price rises by the rate of interest as long as the rate of extraction exceeds the MER, marginal perturbations within this phase cannot strictly increase social surplus. Reducing extraction early in the final phase makes an expansion of the same magnitude feasible later in the phase. Since the net gain and net loss have the same discounted value, such a perturbation will not alter discounted social surplus. For similar reasons, marginal perturbations within the last phase cannot strictly increase discounted social surplus. However, it may seem initially as if social surplus could be strictly increased by expanding extraction in the first phase and reducing it by an equal amount in the last phase since the discounted net marginal utility in the final phase is strictly smaller (by the factor $1 /(1+\gamma))$ than in the initial phase. Such an arbitrage is infeasible, however. A one-barrel reduction in extraction in the last phase does not permit an expansion of extraction in the first phase of an equal amount. It permits an expansion then of a mere $1 /(1+\gamma)$ barrels - the remaining $\gamma /(1+\gamma)$ barrels would be trapped underground as a consequence of expanding extraction which already exceeds the MER. Hence even though extracting one barrel less in the last phase sacrifices in discounted terms only $1 /(1+\gamma)$ of the net utility which would be gained if one barrel were extracted in the first phase, in fact the gain in the first phase would be only $1 /(1+\gamma)$ as large since only that fraction of an additional barrel could be extracted. As a result, there would be no gain from the proposed arbitrage and none if that arbitrage were reversed.

Note that in all of these cases, the marginal benefit associated with optimal extraction $\left(U^{\prime}(x)\right)$ rises by less than the rate of interest. It follows that there is no incentive for the planner to store oil above ground even if it could be done costlessly. Consequently, the extraction path described above is optimal even if the resource may be stored. ${ }^{22}$

\subsection{Free-Access Equilibrium When Speed of Extraction Reduces Ultimate Recovery}

We now examine how the same reservoir would be exploited under free access. Consider first the case where storage is infeasible. Graphically, extraction at each

${ }^{21}$ It is straightforward to define $d$ analytically. Note that if the initial stock is $\bar{S}_{0}$, extraction remains at $E$ for the full $d$ years. Since $C^{\prime}(E)+\bar{\lambda}(1+\gamma)=U^{\prime}(E)$ at the outset while $C^{\prime}(E)+\bar{\lambda} e^{r d}=U^{\prime}(E)$ at the last instant of this phase, $d=\frac{1}{r} \ln (1+\gamma)$.

${ }^{22}$ This is reminiscent of the debate between economists and biologists over the optimality of the maximum sustainable yield. In each case, the economist focuses on when consumption occurs while the noneconomist focuses instead on the total amount consumed. 
point in time can be read from the diagram in Fig. 2 as the horizontal component of the point of intersection of the downward-sloping demand curve $\left(U^{\prime}(x)\right)$ and the upward-sloping average cost curve. Note that neither of these two curves shifts over time. Moreover, since the average cost curve lies uniformly below the marginal cost curve, it lies uniformly below the full marginal-cost curve. This implies that extraction under free access in the no storage case is initially faster than is socially optimal. Moreover, the rate of extraction remains constant in the freeaccess case while socially optimal extraction weakly declines over time. This implies that extraction under free access exceeds socially optimal extraction as long as there remain reserves to exploit. Extraction would therefore terminate sooner in the freeaccess case. If faster extraction, in addition, reduces ultimate recovery, this would be an independent force causing extraction in a free-access equilibrium to terminate sooner than socially efficient extraction. Moreover, under free access, ultimate recovery would be suboptimal as well.

Suppose instead that the resource could be privately stored above ground at zero cost. As we have seen, there are two cases to distinguish. In the first, equilibrium extraction remains at $A C^{-1}\left(p^{*}\right)$ for an interval of time and then strictly increases until reserves are depleted; in the second, equilibrium extraction begins at the faster rate $A C^{-1}\left(\alpha^{*}\right)$ and then strictly increases until reserves are exhausted. Hence, in both cases, equilibrium extraction under free access begins faster than socially optimal extraction and weakly increases over time until reserves are exhausted whereas socially optimal extraction weakly declines from its initially lower level. Because extraction under free access is uniformly faster with storage than without it, extraction would cease sooner. If faster extraction reduces ultimate recovery, this would be an independent force causing extraction under free access to terminate sooner and with less ultimately recovered when storage is feasible. Let $T$ denote the time when extraction ceases and $R$ denote the reserves ultimately recovered. Let the first subscripts $f a$ and $p$ refer to the free access case and the social planner case, respectively; let the second subscripts $s$ and $n s$ refer to storage and no storage, respectively. Then we may summarize our conclusions as follows: $T_{f a, s}<T_{f a, n s}<T_{p, s}=T_{p, n s}$ and $R_{f a, s}<R_{f a, n s}<R_{p, s}=R_{p, n s}$. The three panels of Fig. 3 summarize other aspects of the comparison between the social optimum on the one hand and extraction under free access (with or without storage) on the other.

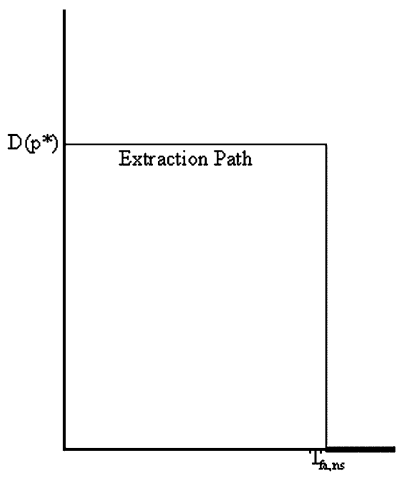

Time (t)

(a) Equilibrium with No Storage

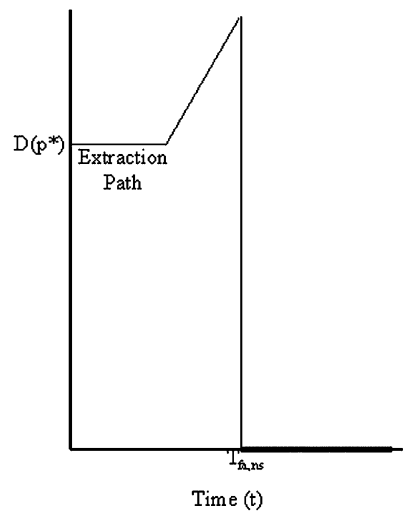

(b) Equilibrium with Storage

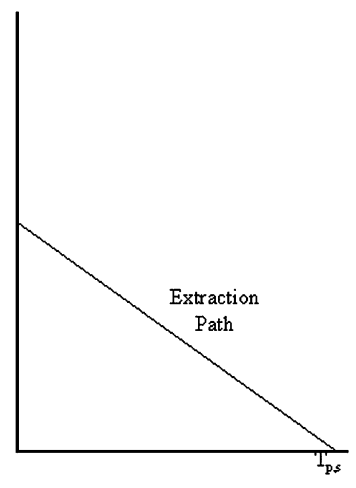

Time (t)

(c) Social Optimum (with or without Storage)

FIGURE 3 


\subsection{Is the Ability to Store Common Reserves as}

Private Stockpiles Socially Beneficial?

The following question naturally arises: does welfare necessarily increase because of the availability of a storage technology combined with a legal regime which treats property extracted from common property as private property? It is to this normative issue which we now turn.

There are two conflicting considerations. On the one hand, the social cost of transferring common reserves to private storage may be high. On the other hand, once the transfer is accomplished and the stocks are privately held, they will be allocated efficiently. As we will see, either of these two effects can dominate. To examine these two effects in the starkest setting, we omit considerations of the MER until the end.

To isolate the beneficial effect of storage, consider the extreme case where extraction is costless. As a benchmark, consider first the extraction path which maximizes discounted surplus. Since extraction cost is assumed to be zero, the marginal benefit must rise by the rate of interest from a level which induces cumulative demand equal to the initial stock.

Next, consider the extraction path which occurs if the initial reserves are instead subject to the rule of capture. Since the average cost curve is horizontal (at zero), the accumulation phase will be instantaneous. Provided the initial stock is sufficiently small $\left(S_{0}^{c} \leq S_{0}^{c *}\right)$, the speculative attack would occur at the outset and the allocation to consumers over time would coincide with the socially efficient allocation. Since, in the case posited, privatization of the common property via storage is costless, this equilibrium is socially efficient.

Strictly lower discounted surplus would result in this example if the ability to store above ground were eliminated. For, extraction would proceed at the faster rate $D(0)$ until reserves were exhausted and would then cease altogether. This feast-or-famine intertemporal allocation is suboptimal (Hotelling [14]). Hence, the availability of a technology permitting the costless transfer of underground reserves to aboveground stockpiles combined with their subsequent legal protection as "private property" is beneficial. It would rectify the inefficiency and would result in the first-best allocation.

This method of privatization, however, is not always so benign. To see why the availability of the storage technology may also lower welfare, consider another extreme case-where the demand curve is rectangular and extraction is costly. It is then socially efficient to deplete the underground reserves at a uniform rate until they are exhausted. This is precisely the equilibrium allocation which would occur in the absence of any storage technology. The rate of extraction and the market price are, respectively, the horizontal and vertical components of the point where the rectangular demand curve and the horizontal average cost curve intersect. Hence, extraction under the rule of capture is, in the absence of any storage technology, socially optimal.

If extraction from the common entails a positive cost, the availability of a storage technology can only lower welfare. Suppose that the average cost is constant and reserves are sufficiently low so that a speculative attack occurs in the first instant. Then, the consumers would receive the socially efficient allocation over time but the cost of providing it would be unduly high because the transfer of underground 
reserves to the private stockpiles is expensive. If rapid extraction reduced ultimate recovery, the availability of the storage technology would be even more harmful.

\section{SPECULATIVE ATTACKS INDUCED BY TOTAL ALLOWABLE CATCH QUOTAS}

The plan for cod, haddock, and yellowtail was initiated in 1977 and established a total quota for each of the stocks of fish. Fishing licenses were required, but they were easily available and there was no moratorium on entry as there was in the surf clam and ocean quahog fishery. It was soon discovered that with the existing fleet and the many new entrants, the annual quota would be harvested very early in the year. This infuriated fishermen. In the following year the quota was caught early in the year [again]. (Anderson [1, p. 174])

Massachusetts placed a ceiling on the aggregate catch of stripers [striped bass] by commercial fishers. Unfortunately, this is a very poor way to control fishing, because it encourages each fishing boat to catch as much as it can early in the season before other boats bring in enough to reach the aggregate quota that applies to all of them. This is precisely what happened last year. (Becker [4])

Although we have referred to oil while analyzing our model, our analysis can easily be applied to other resources as well. To illustrate, we apply it to total allowable catch quotas which have been used to regulate fisheries. As discussed in the Introduction, such quotas have resulted in frenzied races, with much of the catch being frozen for storage.

Suppose as an initial simplification that the reserves subject to the rule of capture are infinite so that the equilibrium price would remain $p^{*}$ forever. Suppose now that the government imposes a limit on cumulative extraction per year (denoted $\bar{Q}$ ). Suppose that the cumulative catch in the original equilibrium exceeds the proposed limit. Then the cumulative restriction imposed by the government substitutes for the cumulative restriction which nature imposes on a resource of finite size and the equilibrium has precisely the qualitative characteristics described in Section 2. That is, in the new equilibrium, the price will remain constant for $\theta^{*}$ weeks during which extraction will occur at the uniform rate, $D\left(p^{*}\right)$. Then private storage begins, ceasing $\nu^{*}$ weeks later when everything which is allowed has been extracted and the cumulative catch limit imposed by the government is filled. If the average cost of extraction is horizontal, $\nu^{*} \rightarrow 0$ and, after the delay of $\theta^{*}$ weeks, the remainder of the catch limit is filled in "the twinkling of an eye." Alternatively, if the average cost curve is upward sloping, the remainder of the catch limit is filled during a frenzied interval of $\nu^{*}>0$ weeks. The two panels of Fig. 4 illustrate a speculative attack induced by a cumulative catch limit. Note that in this reinterpretation of our results from Section 2, what is "drained" after $\nu$ weeks in the accumulation phase of storage is not the reserves remaining under the sea but instead the slack remaining in the cumulative catch constraint.

The government policy which triggers this attack bears no resemblance to the bufferstock policies studied in the literature on speculative attacks. What is identical is the precipitous behavior these policies induce. The evidence is abundant that policies of this kind have the effects predicted.

To conclude this discussion of induced attacks, our simplifying assumption of an infinite stock can now be relaxed. Precisely the same phenomenon will occur if 

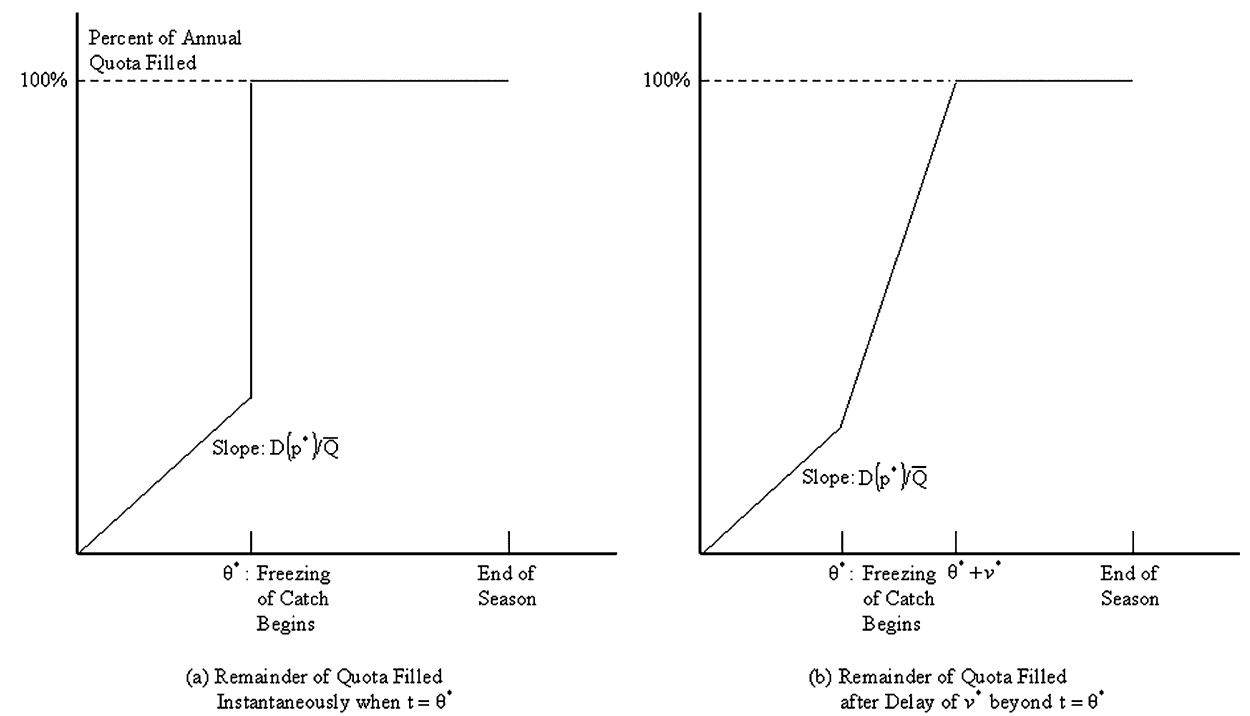

FIGURE 4

the initial reserves, rather than being infinite, are instead finite but growing rapidly enough that, in the absence of the government total catch limit, reserves exist to satisfy indefinitely the demand at the constant price $p^{*}$. The imposition of the cumulative catch limit would then have the effects described above and depicted in Fig. 4. Instead of the resource being extracted at a uniform rate indefinitely, after $\theta^{*}$ weeks the remainder of the catch is suddenly filled (or filled after a short additional interval of $\nu^{*}$ weeks).

Given the foregoing observations, we can ask whether the policy of a seasonal catch limit is necessarily welfare improving. It is straightforward to construct an example where the policy is harmful. Reconsider the case where the average cost curve is strictly positive but horizontal and the demand curve is rectangular. Assume that the stock is either infinite or at least sufficient to permit continual extraction at the rate $D\left(p^{*}\right)$. Then in the absence of a catch limit, marine reserves would be extracted continually at the socially optimal rate-a first-best outcome. However, a catch limit will trigger a speculative attack: usage will be unchanged (although consumers will no longer receive fresh fish throughout the year but instead frozen fish after the induced attack). But welfare will be lower since fishing costs would be incurred long before the fish were to be eaten. Catch limits may, therefore, harm social welfare. Since storage may in fact be costly (fish, unlike oil, must be frozen) and the frenzied extraction the policy induces may have long-run adverse effects on the fish population, the harm to social welfare from the policy will be even greater.

\section{CONCLUSION}

Many resources extracted under the rule of capture are not utilized immediately but are stored instead for later use: oil is stockpiled; fish are frozen; groundwater is bottled; rivers are dammed; land, deforested as the way to establish title, remains uncultivated. We examine the positive and normative effects of adding such storage to the standard model of extraction under free access and apply our findings 
to the "oil rush" and races induced by total catch quotas governing fisheries. Other things being equal, the opportunity to store results in faster depletion. The accelerating accumulation that occurs when the common is drained (or the total catch quota filled) and the extracted resource stored is interpretable in limiting cases as a speculative attack.

When storage is possible, the presence of common property affects the order in which resource pools are exploited. When two private pools have the same constant marginal cost of extraction, the order of their extraction is indeterminate. When one of them is common property, however, it will be exhausted before extraction from the privately owned pool even begins. In fact, extraction from the private pool may be delayed until after the reserves subject to the rule of capture are fully drained even when the private pool is cheaper to extract.

Finally, from a normative point of view, the beneficial effects of privatization may be offset by the social costs of transforming the commons into legally sanctioned private stockpiles. This can occur even if we neglect the possibility that an increased speed of extraction reduces ultimate recovery.

\section{REFERENCES}

1. L. G. Anderson, Marine Fisheries, in "Current Issues in Natural Resource Policy" (P. Portney, Ed.), Johns Hopkins Univ. Press, Baltimore (1982).

2. A. Angelsen, Agricultural expansion and deforestation: modelling the impact of population, market forces and property rights, J. Devel. Econom. 58, 185-218 (1999).

3. M. Asafuddowlah, Sharing of transboundary rivers: the Ganges tragedy, in "The Peaceful Management of Transboundary Resources” (G. Blake, W. Hildesley, M. Pratt, R. Ridley, and C. Schofield, Eds.), Kluwer, London. (1995).

4. G. Becker, How to scuttle overfishing? Tax the catch, Busi. Week, Sept. 18 , p. 30 (1995).

5. The Economist, A fisherman's tale, Economist, May 23 (1998).

6. S. Eskenazi, The biggest pump wins, available under "news" at www.saveourspringsinc.org (1999).

7. R. Flood and N. Marion, Perspectives on the recent currency crisis literature, Internat. J. Finan. Econom. 4, 1-26 (1999).

8. K. Frederick, Water as a Source of international conflict, Resources, issue 123, (1996).

9. R. J. Gilbert, Optimal depletion of an uncertain stock, Rev. Econom. Stud. 46, 47-58 (1979).

10. H. S. Gordon, The economic theory of a common property resource, J. Polit. Economy 62, 124-42 (1954).

11. G. Hardin, The tragedy of the commons, Science 162, 1243-1248 (1968).

12. O. C. Herfindahl, Depletion and economic theory, in "Extractive Resources and Taxation" (M. Gaffney, Ed.) Univ. of Wisconsin Press, Madison (1967).

13. F. Homans and J. Wilen, Markets and rent dissipation in regulated open access fisheries, mimeo, Department of Agricultural and Resource Economics, Univ. of California at Davis (2000).

14. H. Hotelling, The economics of exhaustible resources, J. Polit. Econom. 39, 137-175 (1931).

15. J. Ise, "The United States oil policy," Yale Univ. Press, New Haven, CT (1926).

16. D. Karp, When Perrier came to Texas, the water left, St. Petersburg Times (Dec. 16, 1997).

17. R. King, Sinking fast: how factory trawlers are destroying U.S. fisheries, adapted by J. Townsend for posting on www.greenpeace.org/ oceans/globaloverfishing/sinkingfast.html (1996).

18. E. Koch, Parting the farmers and their water, The Mail and Guardian, Dec. 2, available at www.mg.co.za/mg/news/96nov2/02dec-water.html (1996).

19. M. Kremer and C. Morcom, Elephants, Amer. Econom. Rev. 90, 212-234 (2000).

20. P. Krugman, A model of balance-of-payments crises, J. Money Credit Banking 11, 311-325 (1979).

21. S. A. Leake, "Land subsidence from ground-water pumping," US Geological Survey, available at http://geochange.er.usgs.gov/sw/changes/anthropogenic/subside/ (1997).

22. G. Libecap and S. Wiggins, Contractual responses to the common pool: prorationing of crude oil production, Amer. Econom. Rev. 74, 87-98 (1984).

23. J. W. McFarland, "A selected review of maximum efficient rate (MER) and related resource economics literature," Los Alamos Informal Report LA-6322MS (1976). 
24. J. A. O'Connor, Jr., The role of market demand in the domestic oil industry, Arkan Law Rev. 12, 342-352 (1958).

25. D. F. Prindle, "Petroleum politics and the Texas railroad commission," Univ. of Texas Press, Austin (1981).

26. S. Salant and D. Henderson, Market anticipations of government policies and the price of gold, J. Polit. Econom. 86, 627-648 (1978).

27. H.-W. Sinn, Common property resources, storage facilities and ownership structures: a Cournot model of the oil market, Economica 51, 235-252 (1984).

28. Supreme Court of Texas, Bart Sipriano et al. petitioners versus Great Spring Waters of America, Inc. a.k.a. Ozarka Natural Spring Water Co. a.k.a. Ozarka Spring Water Co. a.k.a. Ozarka, Respondents, No. 98-0247, opinion by Craig T. Enoch, May 6 (1999).

29. A. Tornell and A. Velasco, The tragedy of the commons and economic growth: why does capital flow from poor to rich countries? J. Polit. Econom. 100, 1208-1231 (1992).

30. S. Vinogradov, The legal status of the Caspian Sea and its hydrocarbon resources, in "Boundaries and Energy: Problems and Prospects" (G. Blake, M. Pratt, and C. Schofield, Eds.) Kluwer, London (1998). 